of plastic contact holders.

The entire contact holder bulk was covered with 45 percent nitric acid, upon which base metal dissolution began, this being accomplished within 40 to $50 \mathrm{~min}$. The released nitrogen dioxide gas was sucked by a water jet suction pump $\mathrm{H}$ through two absorption vessels $F$ and $G$, containing concentrated sodium hydroxide solution. Following the base metal dissolution, the used acid with the gold film suspension was released through a plastic sieve $D$. The gold film remained on the sieve and the used acid was collected on the bottom of the vessel $E$. The used acid could be neutralized with quick lime in vessel $\mathrm{I}$.

This procedure guarantees a 100 per cent chemical recovery of gold. However, the overall gold recovery does not exceed 95 per cent due to the mechanical losses of gold film through the separation sieve and in the lining of the plastic contact holders. The final gold recovered from 300 processed contactors amounted to 11.0 to 11.3 $\mathrm{g}$ of pure gold in film form.

\section{Concluding Remarks}

By applying the procedure discussed above, the economic opportunity of gold recovery from low voltage contactors as described is very encouraging, but depends very much on the cost of the operations involved in the opening of the metal cases and removal of wire ends.

The acid consumption and chemical operation costs represent 35 to 40 per cent of the total operating costs.

It goes without saying that on a large industrial scale the economic effects would be much more beneficial than on batch pilot plant scale. However, even in the U.S.A. at the present gold price levels the regional availability of used contactors would not appear to justify the setting up of an industrial recovery plant.

A well-organized and coordinated collection programme for gold-containing electronic waste material carried out by companies may well be a promising alternative for the purpose of gold recycling.

\section{References}

1 T.D. Cooke, Gold Bull., 1982, 15, (2), 38-42

2 Ch. Glynn and R. Conley, Gold Bull, 1979, 12, (4), 134-139

3 M. Antler, Gold Bull., 1971, 4, (3), 42-46

4 F. Ambrose and B.W. Dunning Jr., 'Precious Metals Recovery from Electronic Scrap' in 'Proc. Miner. Waste Util. Symp.', 1980, pp. 184-197

5 D. Takacs et al., 'Industrial Gold Recovery, Especially from Scrap-Electric-Circuit Boards', Hung. Pat. C1 C22B11/040, June 28, (1980)

6 F. Ambrose and B.W. Dunning, Jr., 'Mechanical Processing of Electronic Scrap to Recover Precious Metal-Bearing Concentrates' in 'Precious Metals', edited by R.O. McGachie and A.G. Bradley, Pergamon Press Canada Ltd., 1981, pp. 67-76

7 J.R. Valentine, et al., 'A pparatus and Method for Recovery of a Precious Metal in Pure or Alloyed Form from a Bimetallic Material', Ger. Offen. 3037 112(1981)

\title{
Gold Cluster Labelling for Electron Microscopy
}

\section{HIGH RESOLUTION MARKING OF CARBOHYDRATE SITES ON GLYCOPROTEINS}

Scanning transmission electron microscopes (STEM) are able to image single heavy metal atoms due first to the high contrast and high electron collection efficiency of the dark field annular collector of the system, and secondly to the high resolution which can be obtained with a field emission gun coupled to low-operation lenses. As a result of this facility biologists have shown much interest in using STEM to 'spot' heavy atom markers attached to organic molecules to help in structural studies. Such labelling can be carried out with a high degree of selectivity or specificity.

The application of single heavy metal atoms to label isolated noncrystalline macromolecules has been limited by a number of significant obstacles. In particular the heavy electron dose required for reliable heavy atom detection $\left(10^{3}\right.$ to $\left.10^{5} \mathrm{e} / \AA^{2}\right)$ is considerably higher than that at which most biological molecules suffer damage ( 1 to $10 \mathrm{e} / \AA$ ). Furthermore, single heavy atoms have been observed to migrate following radiation damage which would tend to reduce the level of specificity achieved.

The use of gold colloids has gone some way towards overcoming the above limitations. Another promising avenue has been the use of stable complexes or clusters of heavy atoms and, to this end, the reported application of an undecagold phosphine cluster $[(p-$ $\left.\left.\mathrm{H}_{2} \mathrm{NCH}_{2} \mathrm{C}_{6} \mathrm{H}_{4}\right)_{3} \mathrm{P}_{7} \mathrm{Au}_{11}\right]^{3+}$ containing a central core of 11 gold atoms surrounded by an organic 'shell' of total radius of about $10 \AA$ J.S. Wall et al., Ultramicrosc., 1982, 8, 397-402) is particularly exciting.

A number of important advantages result from marking with the undecagold phosphine cluster instead of with a single heavy,metal atom. In particular the gold core can be located in the electron microscope at a much lower electron dose $\left(50 \mathrm{e} / \AA^{2}\right)$, and the cluster shows very little movement upon irradiation - gradual decomposition does however take place with loss of half its intensity at a dose of some $10^{3} \mathrm{e} / \AA^{2}$. The resolution which the gold cluster allows is 5 to 10 times better than that achieved with conventional markers such as ferritin (diameter $120 \AA$ ) or ferritin-antibody. Furthermore the surrounding organic 'shell' contains 21 amino groups which can be cross-linked directly or chemically modified, and by suitable organic reactions covalent bonding to specific functional groups on the substrate molecule to be labelled is possible.

More recently (JJ. Lipka et al., J. Ultrastruct. Res, 1983, 84, 120-129) the specific labelling was reported of carbohydrate moieties on the glycoprotein human haptoglobin $(\mathrm{Hp})$ in the haptoglobinhaemoglobin complex (Hp.Hb) which is readily observed in the electron microscope as a barbell shaped molecule.

The carbohydrate moieties of the Hp.Hb complex were oxidized by sodium periodate to produce aldehydes. The primary amines on the undecagold cluster were allowed to react with aldehyde residues to produce Schiff's base linkages which were subsequently reduced with sodium borohydride. High-resolution STEM showed the undecagold label to be localized in a region known to be occupied by the heavy chains of haptoglobin with which the carbohydrate is exclusively associated. The amount of labelling was found to be two to four gold clusters per molecule when excess label was reacted. This report concludes that the high chemical specificity of the reaction and the high resolution of the gold clusters should make this new label of widespread value in studies of other glycoproteins or carbohydrate-bearing molecules.
C.I. 